\title{
Using English Evaluative Adjectives in the Function of the Interjection
}

\author{
Alexander Y. CHURANOV \\ Ph.D. (in Philology) \\ Associate Professor \\ Department of Foreign Languages \\ Balashov Institute of Saratov State University \\ 26 K, Marx Str., Balashov, 412300, Russia \\ $+78454542525$ \\ 021274@mail.ru
}

\begin{abstract}
The article considers using English evaluative adjectives as interjections. Following Bloh, we treat the interjection as a class of functional words within the system of the parts of speech. We believe that the interjection comprises two kinds of units: the ones in the form of a word, a phrase or a sentence used to express emotions and volition ('interjections proper') and those used in the function of the interjection ('interjection-like units'). In accord with that, two subtypes are distinguished: 'adjectival interjections' and 'adjectival interjection-like units'. Both subtypes were analyzed using different linguistic methods in terms of their form, meaning and function in dialogues and monologues taken from British and American novels of the late 20th - the early 21th centuries. The study revealed a tendency to use interjection-like units more often than interjections proper, which can be explained by the fact that interjection-like units allow speakers not only to express their emotions, but also to express their attitudes towards the thing or person in question. The study shows two possible ways for further studies: a) the way other parts of speech used in the function of the interjection and b) the way interjection-like units used in other forms of discourse, especially those of the Internet media types which is the most popular way of communication in the modern world.
\end{abstract}

Keywords: literary text; evaluative adjectives; interjectivation; interjection; interjection-like unit.

\section{Introduction}


For the first time as a separate part of speech the interjection was singled out in the grammar by the ancient Roman scholar Varro in the first century BC. Since that time the interjection has been considered in numerous works on grammar. A large number of dissertations and monographs are devoted to its detailed research. In the late XX and early XXI centuries there has been a significant increase in interest in studying the specific features of interjections in different languages of the world: Russian, Mexican Spanish, English, Spanish, Ossetian, Mongolian, Chuvash, Italian, Turkmen, German and others. In our opinion, that is explained by a number of factors. First of all, the following ones should be noted: a) a growing interest in studying the features of oral colloquial speech, b) steadily increasing attention from researchers to peripheral linguistic units, c) a noticeable increase in the number of studies of the emotive aspect of the way language units function (Kurnosova, 1992).

Despite the large number of studies devoted to the problems of the interjection as a whole, as well as the features of their structure, semantics and use in different languages, little attention is paid to the peculiarities of using other parts of speech in the function of the interjection. For example, the adjective fine is widely used in the function of the interjection to express approval. Meanwhile, many authoritative English dictionaries (see, for example, The Cambridge English Dictionary) do not single out a separate dictionary entry for fine as an interjection. They only mention that use of the adjective fine as one of its many meanings. Consider an example of this kind taken from The Cambridge English Dictionary:

"I'll come to your place at eight." "Fine. ..." (The Cambridge English Dictionary).

As is seen from the example, in this case the use of fine does not differ from such well-known interjections as Wow! Oops! Oh! Well!

Other dictionaries, however, (see the Oxford Learner's Dictionaries) single out the use of this adjective as an interjection:

(also used as an exclamation) used to tell somebody that an action, a suggestion or a decision is acceptable:

'I'll leave this here, OK?' 'Fine' (Oxford Learner's Dictionaries).

This research is devoted to a comparative study of two subtypes of units in the class of interjections: a) interjections that derived from evaluative adjectives ('adjectival interjections') and b) units that are evaluative adjectives, but can be used in the English language in the function of the interjection ('adjectival interjection-like units'). Both subtypes are analyzed in terms of their form, meaning and 
function in dialogues and monologues taken from British and American novels of the late 20th - the early 21 th centuries.

The subtypes of units under study make up only $14.9 \%$ of the total number of interjections in the English language, but they are in frequent use (Kveselevich, Sasina, 2001).

The conducted study shows that speakers often turn to evaluative adjectives used as interjections to express their emotions rather than to interjections proper. In the course of the study of the use of these two subtypes of units in the class of interjections both in dialogues and monologues only two adjectival interjections were found - Dear! Gracious!

As for the adjectival interjection-like units (i.e. the use of evaluative adjectives in the function of the interjection), their number, depending on the national variety of the English language (British or American), amounted to 47: Great! Absurd! Amazing! Bad! Super! Curious! Amusing! Middling! Quiet! Capital! Beautiful! Crazy! Brilliant! Scandalous! Cool! Delicious! Excellent! Divine! Stunning! Exquisite! Fine! Good! Grand! Hilarious! Impossible! Unbelievable! Incredible! Killing! Lovely! Marvie (Marvy)! Marvellous! Outrageous! Queer! Wrong! Ridiculous! Sad! Disgraceful! Shocking! Fantastic! Nice! Smashing! Splendid! Funny! Charming! Swell! Typical! Wonderful! (Churanov, 2008)

Some adjectival interjection-like units are used mostly in British English (Brilliant!) or American English (Crazy! Marvie! Marvy! Nice! Zero cool!). Others are characteristic of slang (Crazy! Swell!).

The fact that adjectival interjection-like units are used more often that interjections proper for expressing emotions, a lack of consistency in dictionary entries, which does not always indicate the possibility of using this or that evaluative adjective as an interjection, and a small number of studies on this topic demonstrate the relevance of this study.

\section{Methods}

In the study, we used a complex technique combining the method of linguistic observation and description, a contextual analysis, the method of analyzing dictionary definitions, the elements of transformational analysis, classification and systematization techniques, and the statistical method.

The object of the study is interjections that derived from evaluative adjectives which were analyzed in terms of their form, meaning and function in dialogues and monologues taken from British and American novels of the late 20th - the early 21 th centuries. The novels used as the material for the study are realistic fiction novels of different genres that are full of elements of colloquial speech: 
historical, romance, detective, sci-fi, adventure. Ten novels were analyzed with a total number of 3899 pages.

In addition, the analysis of the linguistic material was greatly facilitated by the online versions of modern English dictionaries: The Cambridge English Dictionary (The Cambridge English Dictionary), Longman Dictionary of Contemporary English Online (Longman Dictionary of Contemporary English Online), Oxford Learner's Dictionaries (Oxford Learner's Dictionaries), as well as the fundamental work of Russian lexicographers: Kveselevich, Sasina (2001) Russkoanglijskij slovar' mezhdometij (okolo 1000 edinic) [Russian-English Dictionary of Interjections (about 1000 units)].

\section{Literature Review}

The interjection has always been and remains one of the most controversial parts of speech in modern linguistics. Not all linguists unambiguously determine the status of the interjection in the system of the parts of speech, the question of the composition of units of this class is also controversial.

As for the status of the interjection in the system of parts of speech, it either stands out in a special part of speech (Litnevskaya (2018)) or is included in the notional parts of speech (Levkovskaya (2019)), or is considered as functional part of speech (Bloh (2017)), either is not included in the system of the parts of speech and presents a special category of words (Khlenbikova (2004)), or refers to the functional-independent part of speech as a separate class distinguished in language along with independent and functional parts of speech (Sereda (2013)).

In this paper, the interjection is considered as a special functional part of speech in the system of the parts of speech in the English language. When comparing the main class features of the interjection as a part of speech with those of functional and notional parts of speech, the largest number of common features of this class are found with functional parts of speech, namely: word-signals of emotions and volition; morphological unchangeability; heterogeneity of the morphological structure of the units that make up the class; the syntactic openness of the class; the function of the emotional or volitional determinant of a statement or its separate part (Bloh, 2017). The two of the abovementioned features (the specificity of the function performed by interjections as well as the syntactic openness of the class, not characteristic of other classes of functional words) make the interjection a special functional part of speech.

As for the composition of language units included in the class of interjections, some scholars include units in this class that do not possess the necessary categorical features of this part of speech (Kurnosova (1992)), or units that have the necessary characteristics are excluded from the class 
(Tuebekova (1984)). The difficulty in defining a clear class composition of this part of speech is determined mainly by the heterogeneity of language units that can in one way or another fulfill the function of the interjection (i.e. an expression of emotions and volition). Thus, it can be just cries accompanied by some gestures or body reflexes $(U g h !)$ that have nothing to do with ordinary words of language (Strange, 2016). And it can also be ordinary words, phrases or sentences (Yuck! This is a pretty kettle of fish!)

We believe that the class of interjections includes two types of lingual units: the ones in the form of a word, a phrase or a sentence used to express emotions and volition ('interjections proper') and those used in the function of the interjection ('interjection-like units').

In the course of the study we relied on fundamental works on the theoretical issues of English grammar (Bloh (2017), Komova, Alexandrova (2013), Gurevich (2017), Jespersen (1935)), works on the study of the aspects of the use of interjections in language (Sereda (2013), Dybovskiy (1983), Sharonov (2009), Wharton (2003), Ameka (1992), Strange (2016)) and works devoted to the issues of interjectivization in language (Shigurov (2009)).

\section{Results}

Adjective interjections (or pure adjective interjections) are presented in English by a limited number of units of the type Dear! Gracious! They represent the initial word form of the adjective which passed into the class of interjections by means of a functional transition. Dear! expresses sympathy, regret, grief, contempt, surprise, impatience. Gracious! expresses strong anxiety, regret, fear, surprise. In the dialogues, the interjection Dear! is usually used in combination with the interjection $O h !$

"Did he know she was dealing?"

“Oh, dear." Nadine took a long breath, then sighed (Shankman, 1990).

In the monologues the interjection Dear! is often used in combination with the pronoun me:

'...A rum-looking cove. Dear me, a very rum-looking cove.'(O’Brain, 1990).

We have not found cases of the use of the interjection Gracious! Adjective interjections are used as part of interjectional phrases (Goodness gracious me! Dear me!).

The number of adjectives used as part of interjectional phrases is not so much (fine, pretty, crafty, great, dear, good, alive, gracious, holy, little) - A fine kettle of fish! Great snakes! A pretty pair of shoes! O my gracious! and others. Some of them are used only in a particular variant of the English 
language. Thus, the interjectional phrases Good (dear) gramercy! Holy cats! Hot dog! are used mainly in American English.

The number of adjectives used as part of interjectional sentences is even less (holy, soft, high, pink, fine, best, pretty, pretty) - Come hell or high water! This is a pretty kettle of fish!! Strike me pink! Here's a fine (nice) how! and others.

In the case of purely interjectional units, it is occasionally possible to use not only the initial form of an adjective, but also its superlative form. This is found, for example, in the interjectional sentence Put your best foot (leg) forward!

The number of interjectional phrases with an evaluative adjective exceeds the number of interjectional sentences almost twice.

The pure adjective interjections Dear! Gracious! should not be mixed with units such as Excellent! Lovely! and the like, which, too, by their origin, go back to adjectives. The latter have a dual nominative-interjectional nature and are semi-adjectives and semi-interjections (in other words "adjective interjection-like units"), in contrast to the former, having only one -interjectional.

Adjective interjection-like units (otherwise evaluative adjectives used as interjections) are presented in English by a large group of units. The basis for them is the original word form of an evaluative adjective used in the function of the interjection. In terms of semantics, they differ in a rather wide and diverse spectrum of expressed emotions. In the dialogues the use of the evaluative adjective good to express satisfaction prevails. It is possible both its single use, and with the previous primary interjection $o h$ :

“...The preliminary work has all been done.”

“Oh, good." (Beauman, 1988).

In monologues, the use of the evaluative adjective good to express satisfaction also dominates. It is possible both its single use, and a double repetition:

Good...good. This is terrific data, Lieserl (Shankman, 1990).

The use of the adjective great is also common. Consider an example:

Great. Great. That's great,' said Ned grinning happily. 'Okay then. And Rufus, till August, then?' (Beauman, 1988).

In this example, the speaker uses a twofold repetition of the adjective great to enhance its interjection-like function. The example is also interesting in that it is followed by the sentence 
That's great, which demonstrates the fact that evaluative adjectives in the function of the interjection still remain semi-adjectives and do not lose features of this part of speech. In this example, this is manifested in the fact that Great. Great can be considered as an elliptical from of That's great.

\section{Discussion}

In general, the use of adjective interjection-like units prevails in the dialogues.

Evaluative adjectives are used as part of interjection-like phrases and sentences.

The adjectives which are used as part of interjection-like phrases are bad, fine, alive, real, pretty, good, comic, excellent, dead, old, natural, tall, fair, great, funny, good, jolly, strange.

In fact, any evaluative adjective can be used in the function of the interjection. Here is an example from the book by S. Fry “The Stars' Tennis Balls": Except when he's passing through on his way to Scotland to murder grouse. Unbelievable. Unbelievable. (S. Fry, 2004).

The adjectives which are used as part of interjection-like sentences are correct, annoying, right, high, crazy, mad, good, curious, bad, better, nice, absurd, funny, awful, exciting, frustrating, horrible, horrid, maddening, provoking, sweet, terrible, vexing, delightful, terrible, lovely, marvelous, real, fine, great, super, heavy.

In the case of purely interjection-like units, it is occasionally possible to use not only the initial form of an adjective, but also its comparative form. This is found, for example, in the interjectional sentence Couldn't be better! Some interjection-like sentences are intermediate between ordinary exclamatory sentences and the interjection-like sentences - You're crazy!

We have not identified a single case of using the so-called "statives" (glad, sorry, awry, ablaze), i.e. adjectives denoting the temporary state of a person or an object. Emotion is a temporary state, and, theoretically, the speaker can use language units that indicate the temporary state of a person or an objection. Perhaps this will be revealed in the course of further research.

The study showed that the use of interjection-like units prevails both in monologues and in dialogues. We believe that this can be explained by two main reasons. Firstly, the lexical units that are the basis for adjective interjection-like units belong to the most frequent units of the language. Thus, the adjective good is included in the 1000 most common words in spoken language according to the Longman Dictionary of Contemporary English (Longman Dictionary of Contemporary English Online). The second reason is the speaker's desire not only to convey his or her emotional state, but also to assess the object, phenomenon, person, etc., which caused this emotional state. In 
other words, to "explain" to others the reason for such feelings. And this can be done briefly using interjection-like units that simultaneously perform both expressive and nominative (in this case evaluative) functions. In the case of adjective interjection-like units formed from evaluative adjectives, this is also the presence of the adjective which has the evaluative function in its original nature.

\section{Conclusion}

We have analyzed the specific features of the use of interjections and interjection-like units derived from evaluative adjectives in dialogues and monologues.

The results of such studies can be used in various research on the features of spoken English in its British and American national variants.

Interjections and interjection-like units of this type are also widely used in author's monologues, which could be a prospect of further research on the features of the use of this type of interjection and interjection-like units in British and American novels of the period under study.

Of particular interest, in our opinion, is s study of the specific features of the use of interjection-like units of this and other types in various genres of Internet discourse.

\section{Acknowledgements}

I would like to express my sincere gratitude to my supervisor Professor Bloh, head of the Department of Grammar at Moscow Pedagogical State University for helping to develop the concept of contrasting pure interjections and interjection-like units. I would also like to express my thanks to Professor Comuzzi who has been my colleague at Balashov Institute for many years and now head of the Department of Theory and Practice of Translation at Sevastopol State University for her reading the article and for her helpful and valuable comments towards it improvement.

\section{References}

Alexandrova, O.V., Komova, T.A. (2013). Modern English Grammar: Morphology and Syntax. Moscow: Academia.

Ameka, F. (1992). Introduction. Interjections: The universal yet neglected part of speech. Journal of Pragmatics, 18, 101-118.

Beauman, S. (1988). Destiny. Bantam Books. The USA.

Bloh, M.Y. (2017). Theoretical Grammar of the English Language. Moscow: Feniks. (in Russian) 
Churanov, A.E. (2008). An adjectival basis in the formation of the system of English interjections and interjection-like units. Moscow: MPGU (in Russian)

Dubovskiy, A.S. (1983). Universal properties of interjections and their linguistic description. Vladivostok: Far Eastern University Publishing. (in Russian)

Fry, S. (2004). The Stars’ Tennis Balls. Arrow Books.

Gurevich, V.V. (2017). Theoretical grammar of the English language. Comparative typology of the English language and the Russian language. Moscow: Flinta: Nauka. (in Russian)

Jespersen, O. (1935). The Philosophy of Grammar. London: George Allen \& Unwin Ltd, 90-91.

Khlebnikova, I.B. (2004). Essentials of English Morphology. Moscow: CheRo.

Kurnosova, N.A. (1992). The sign status of interjections and the problem of their lexical-graphic processing. Ph.D. thesis. Kyiv. (in Russian).

Kveselevich, D.I., Sasina, V.P. (2001). Russian-English dictionary of interjections (about 1000 units). Moscow: OOO AST Publishing. (in Russian)

Levkovskaya, K.A. (2019). The theory of the word, the principles of its construction and aspects of the study of lexical material. Moscow: URSS. (in Russian)

Litnevskaya, E.I. (2018). The Russian language: a short theoretical course for students. Moscow State University Publishing House. (in Russian.)

Longman Dictionary of Contemporary English Online. Retrieved from: https://www.ldoceonline.com (Accessed on December 19, 2019).

O’Brain, P. (1990). Post Capitan. W. Norton \& Company, William Collins Sons \& Co. Ltd., The USA.

Oxford Learner's Dictionaries. Retrieved from: https://www.oxfordlearnersdictionaries.com (Accessed on December 19, 2019).

Sereda, E.V. (2013). The morphology of the modern Russian language. The place of interjections in the system of the parts of speech. Moscow: Flinta. (in Russian)

Shankman, S. (1990). Now Let's Talk of Graves. New York: Pocket Books.

Sharonov, I.A. (2009). Interjections in a language, in a text and in communication: Ph.D. thesis. Moscow. (in Russian) 
Shigurov, V. (2009). Interjectivization as a type of stepwise transposition of linguistic units in the system of the parts of speech. Moscow: Academia. (in Russian)

Strange, U. (2016). Emotive Interjections in British English: A corpus-based study on variation in acquisition, function and usage. John Benjamins B.V.

The Cambridge English Dictionary. Retrieved from: https://dictionary.cambridge.org (Accessed on December 19, 2019).

Tuebekova, Z.D. (1984). The place of interjections in the system of the parts of speech in modern English: abstract of a Ph.D. thesis. Moscow. (in Russian)

Wharton, T. (2003). Interjections, language and the 'showing'/'saying' continuum. Retrieved from: http://www.phon.ucl.ac.uk/home/PUB/WPL/00papers/wharton.pdf $\quad$ (Accessed on December 19, 2019). 